\title{
Comparative Evaluation of Thermogravimetric and Refractive Index Techniques in Determining Biodiesel Yield
}

\author{
Sirui Li, Ebenezer Miezah Kwofie, Michael Ngadi \\ Department of Bioresource Engineering, McGill University, Ste-Anne-de-Bellevue, QC, Canada \\ Email: michael.ngadi@mcgill.ca
}

How to cite this paper: Li, S., Kwofie, E.M. and Ngadi, M. (2020) Comparative Evaluation of Thermogravimetric and Refractive Index Techniques in Determining Biodiesel Yield. Journal of Sustainable Bioenergy Systems, 10, 30-42.

https://doi.org/10.4236/jsbs.2020.101003

Received: June 13, 2019

Accepted: March 13, 2020

Published: March 16, 2020

Copyright $\odot 2020$ by author(s) and Scientific Research Publishing Inc. This work is licensed under the Creative Commons Attribution International License (CC BY 4.0).

http://creativecommons.org/licenses/by/4.0/

\section{(c) (i) Open Access}

\begin{abstract}
Biodiesel is a clean and renewable resource that consists of mono-alkyl esters of long chain fatty acid, which could be obtained from the transesterification reaction of vegetable oils and animal fats with alcohols and catalysts. Biodiesel yield has typically been determined using expensive and laborious techniques. The attempt of this study was to examine the potential of quantifying the biodiesel conversion in real time using refractive index in transesterification process of canola oil with methanol and $\mathrm{KOH}$. Biodiesel yields at five different mixing intensities and reaction times were measured using a refractometer. The measured results were then compared with analytical data obtained from thermogravimetric analysis (TGA) technique over a temperature range of $25^{\circ} \mathrm{C}-600^{\circ} \mathrm{C}$. Experimental results indicated that the FAME conversions at different mixing intensity and reaction time measured from refractometer correlated well to the relative weight losses from TGA method with $\mathrm{R}^{2}=0.93(\mathrm{p} \leq 0.05)$; however, the refractometer may over-estimate the biodiesel yield when the reaction rate was too low. Overall, the refractometer technique is cheaper and easier to manage and could provide a reliable prediction of biodiesel yield in real time.
\end{abstract}

\section{Keywords}

FAME, Thermogravimetric Analysis, Refractive Index, Mixing, Real-Time Monitor

\section{Introduction}

Fossil fuels, including oil, coal, natural gas, are still the leading energy for human activities. However, these resources, which were formed over hundreds of mil- 
lions of years, are non-renewable and will run out in the near future [1]. Nevertheless, the burning of traditional fossil fuels results in high emissions of air pollutants, such as $\mathrm{CO}_{\mathrm{x}}, \mathrm{SO}_{\mathrm{x}}, \mathrm{NO}_{\mathrm{x}}$ and ambient PM2.5, leading to the greenhouse gas effects and affecting human health. Therefore, it is urgent to find clean and renewable resources. Biodiesel is one of these alternatives, which could be obtained from vegetable oils and animal fats by the reaction with alcohols with the presence of catalysts through transesterification process in mild condition.

Numbers of biodiesel characterization methods have been proposed and investigated by many researchers, including thermogravimetric analysis (TGA), gas chromatography (GC), near-infrared spectroscopy (NIRS), and high-performance liquid chromatography (HPLC) and Proton nuclear magnetic resonance $\left({ }^{1} \mathrm{H}\right.$ NMR) spectroscopy [2] [3] [4] [5] [6]. Among all these methods, ${ }^{1} \mathrm{H}$ NMR spectroscopy is widely accepted as the standard characterization method [3] [4] [7]. However, these methods have some drawbacks. For example, they may require a pretreatment for samples, which is time consuming; meanwhile, tedious calibrations are usually needed before data analysis; nevertheless, very expensive instrument has to be equipped and experienced technicians are needed to collect and analyze data [8].

TGA is a less expensive technique to characterize the thermal stability of materials and assess the conversion of biodiesel yield when compared with the mentioned techniques without requirement of pretreatment [9]. It measures the changes of physicochemical properties in different materials as weight changes under increasing temperature. Chand, Reddy [4] quantified the biodiesel production from alkali-catalyzed transesterification of soybean oil using TGA method by comparing the estimated biodiesel percentages with the values from ${ }^{1} \mathrm{H}$ NMR spectroscopy. They have demonstrated that TGA method had comparable performance with ${ }^{1} \mathrm{H}$ NMR spectroscopy in determining the biodiesel yield with good agreement (within 1.5\%) and TGA was a simpler, faster, and more economical technique to monitor biodiesel production. Farag, El-Maghraby [6] examined the biodiesel conversion under different reaction temperatures, time and alcohol to oil ratio, catalyst concentration and variety using TGA and GC method. The results of biodiesel conversion measured from two analytical methods were found to be similar and fit each other linearly with an $\mathrm{R}^{2}$ of 0.998 .

Although TGA does not require pretreatment of samples, it cannot provide real time monitoring of biodiesel conversion because it requires heating of samples, which may take a few hours. Comparatively, the characterization of biodiesel using refractometer is much cheaper than TGA and has a higher time resolution. The method of using refractive index for biodiesel synthesis monitoring was first examined by Xie and Li [8]. They found that the yields of methyl ester from soybean oil with ethanol estimated by refractive index were within $4 \%$ error when compared with the results from ${ }^{1} \mathrm{H}$ NMR. Other investigators have also reported using refractometers for biodiesel characterization from soybean oil [10], canola oil [11], microalgae [12], linseed oil [13], Pongamia pinnata [14], 
rapeseed oil [15], etc. However, these studies did not sufficiently evaluate the application of refractometer as a method for monitoring the extent of oil to biodiesel conversion at any time during the transesterification process.

Therefore, the objective of the present work is to test the agreement of TGA and refractometer for determining FAME content from the transesterification process in canola oil and methanol with $\mathrm{KOH}$, and thereby to evaluate the performance of refractometer for analyzing real time biodiesel production in research and industrial settings.

\section{Methods and Materials}

\subsection{Materials}

Canola oil was obtained from Montreal local market. HPLC grades of methanol (99.8\%) was purchased from Fisher Scientific. Potassium Hydroxide (86.4\%) was purchased from Fisher Scientific as the chemical catalyst. Biodiesel standard for the calibration was purchased from LGC Standards (USA).

\subsection{Experimental Setup}

The biodiesel production set up consisted of a 1-L glass reactor, an overhead agitator was equipped with a digital display unit and a two flat-blade paddle agitator. The impeller diameter and the blade width were $60 \mathrm{~mm}$ and $20 \mathrm{~mm}$, respectively. The speed range of the agitator varied from $80 \mathrm{rpm}$ to $1000 \mathrm{rpm}$. A Thermo Scientific Sorvall Legend XT centrifugation was used for separating the materials in each sample.

The methanol: oil volume corresponding to a molar ratio of 6 was estimated at 1:3.96. All the experiments were conducted at room temperature $\left(25^{\circ} \mathrm{C} \pm 1.5^{\circ} \mathrm{C}\right)$ and atmospheric pressure. The impeller speeds were 200, 250, 275, 300 and 325 rpm to cover the whole range of mixing from immiscible phase to uniform dispersion. The blade was set at $1 / 2 \mathrm{H}(47.5 \mathrm{~mm}$ from the bottom). The total height (H) of the emulsion was $95 \mathrm{~mm}$. Figure 1 shows the set-up for the experiment.
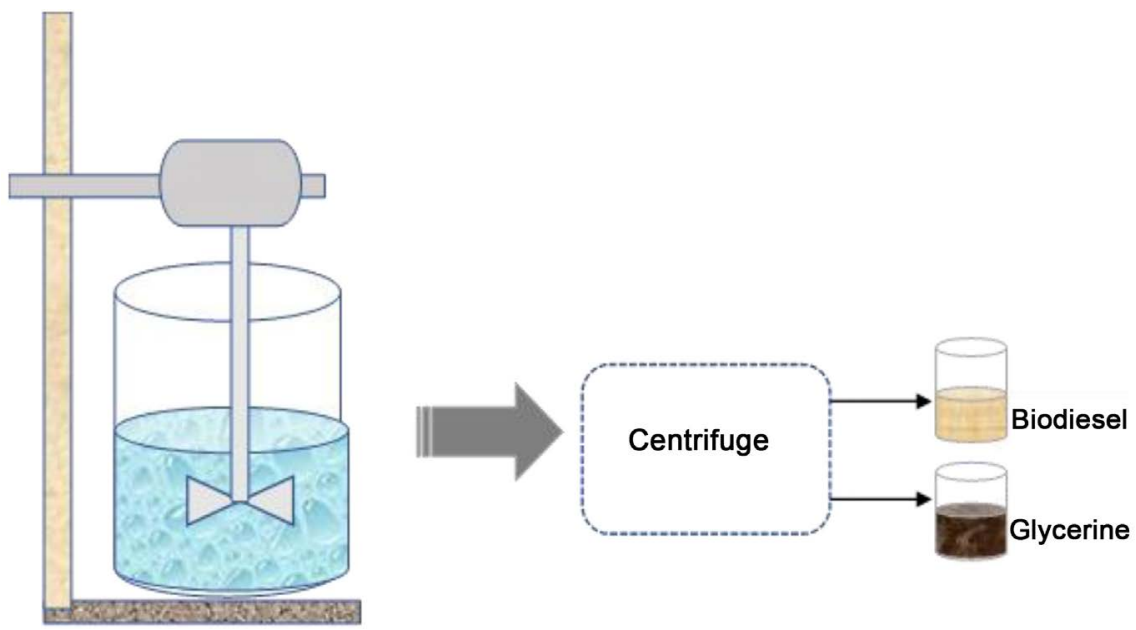

Figure 1. Schematic diagram of experimental set-up. 


\subsection{Experimental Procedures}

The biodiesel was produced with canola oil and methanol with $\mathrm{KOH}$ as catalyst. $2.74 \mathrm{~g}$ of potassium hydroxide was dissolved in $100 \mathrm{ml}$ of methanol in a conical flask. The mixture was continuously stirred until all the $\mathrm{KOH}$ were dissolved into the methanol. Afterwards, $595 \mathrm{ml}$ of canola oil was poured into the reacting vessel, followed by $50 \mathrm{ml}$ of pure methanol. After the two solutions were separate and stable, the remaining $100 \mathrm{ml}$ of the methanol was added gently with $\mathrm{KOH}$. The agitator is then started at the preset speed to attain a specific rpm (200, 250, $275,300$ or 325$)$.

To investigate the processes of transesterification reaction, $5 \mathrm{ml}$ sample was withdrawn from the mixing reactor by a 2 -ml pipette during the agitating process at different times. To ensure sample was taken randomly, each sample set was drawn from bottom, middle and top of stirred vessel for a proper representation of the entire sample. The reaction was stopped at the set time with the immediate addition of few drops of $\mathrm{pH} 6.2$ phosphate buffer and allowed to stay for $5 \mathrm{~min}$. The sample was then centrifugated at $3500 \mathrm{rpm}$ for $5 \mathrm{~min}$ after which it was separated into upper phase (biodiesel and residual canola oil) and lower phase (methanol, glycerine and rest buffer). The lower phase was decanted, and the upper phase was kept in the refrigerator for further analysis.

\subsection{Analytical Methods}

Thermogravimetric analysis (TGA) of the unwashed biodiesel was conducted by $10 \mu \mathrm{L}$ samples of biodiesel/oil mixture heated at a constant heating rate of $10^{\circ} \mathrm{C} / \mathrm{min}$ in the nitrogen atmosphere in a titanium pan. The temperature ranged from $25^{\circ} \mathrm{C}$ to $600^{\circ} \mathrm{C}$. Based on previous TGA study, the heating rate of $10^{\circ} \mathrm{C} / \mathrm{min}$ has been reported to be a reliable heating rate and it minimizes experimental error compared with other heating rates [4].

Refractometer analysis was considered as a simplified alternative method to several analytical methods including the thermogravimetric analysis used in the study [16]. A handheld grand index refractometer model (RND025/ATC) with refractive index range of $1.435-1.520$ and 0.001 graduation were used in determining the biodiesel yield. A calibration curve was developed with pure biodiesel and canola oil mixtures at different ratios. All measurements were taken in triplicates.

\subsection{Statistics for the Comparison between Methods}

The performance of the refractometer in determining the biodiesel yield was estimated using the calibration curve. The computed biodiesel yields from refractive indexes were compared with the TGA results using two statistical indices, including the percent bias (PBIAS) and coefficient of determination $\left(R^{2}\right)$. Percent bias (PBIAS) determines the difference of mean values between refractometer and TGA measured values (Equation (1)). Coefficient of determination $\left(R^{2}\right)$ is defined as the proportion of variation of $y$ data that was explainable by 
variation in $\mathrm{x}$ data (Equation (2)) [17].

$$
\begin{gathered}
\text { PBIAS }=\frac{x_{i}-y_{i}}{x_{i}} \times 100 \% \\
R^{2}=1-\frac{\sum_{i=1}^{n}\left(y_{i}-x_{i}\right)^{2}}{\sum_{i=1}^{n}\left(x_{i}-x_{a}\right)^{2}}
\end{gathered}
$$

where $x_{i}$ is the biodiesel yield from TGA, $y_{i}$ is the computed yields by refractive index, $\mathrm{n}$ is the total number of measurements, $x_{a}$ is the average value of TGA measured yields.

\section{Results and Discussion}

\subsection{Analytical Evaluation Using Thermogravimetric (TGA)} Impact of Agitation Speed on Biodiesel Yield

Typical TGA thermographs for biodiesel production over the mixing time are shown in Figure 2. The impacts of the mixing speed are also shown in Figure 3. The results showed a general exponential rise in biodiesel production as the mixing progresses. As anticipated, the biodiesel yield at the beginning of the process was minimal for all rpm selected. This low initial yield can be attributed

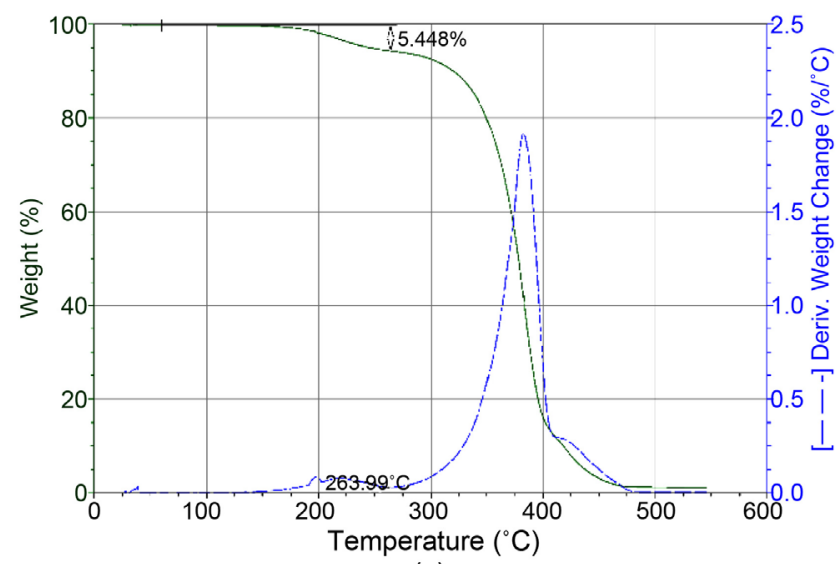

(a)

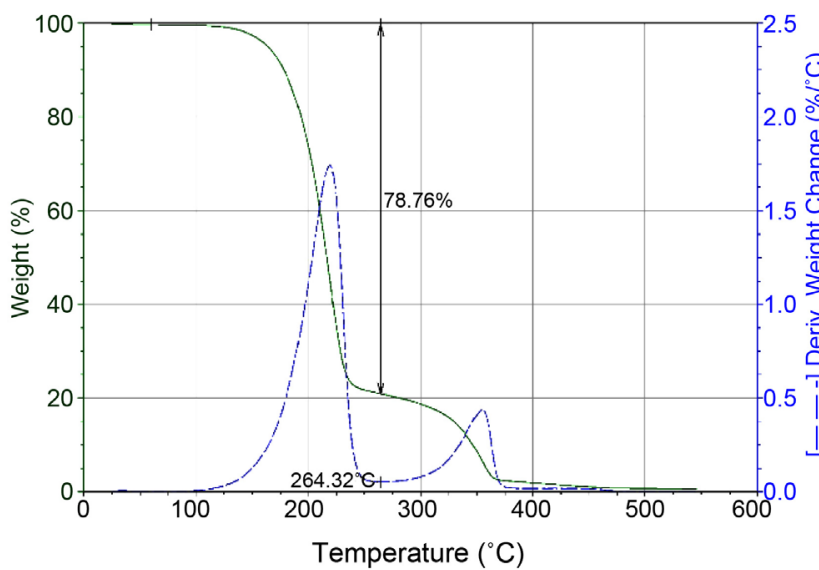

(c)

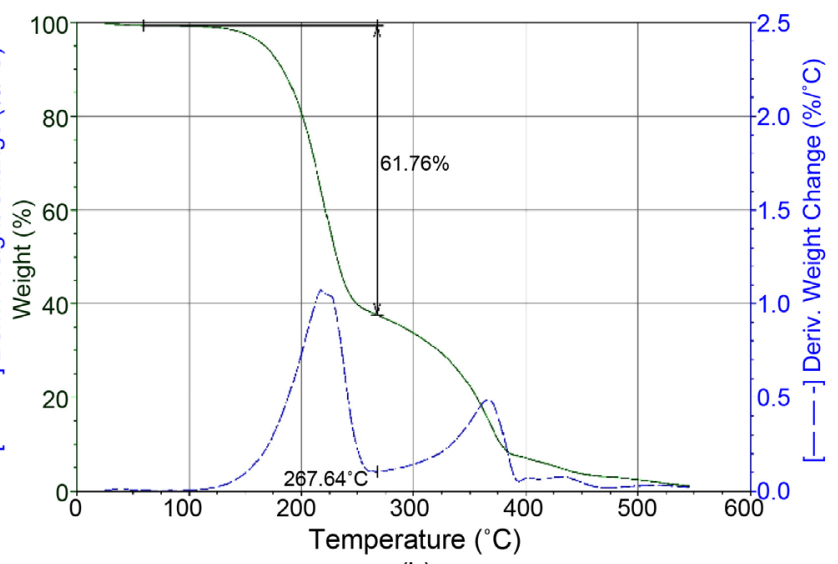

(b)

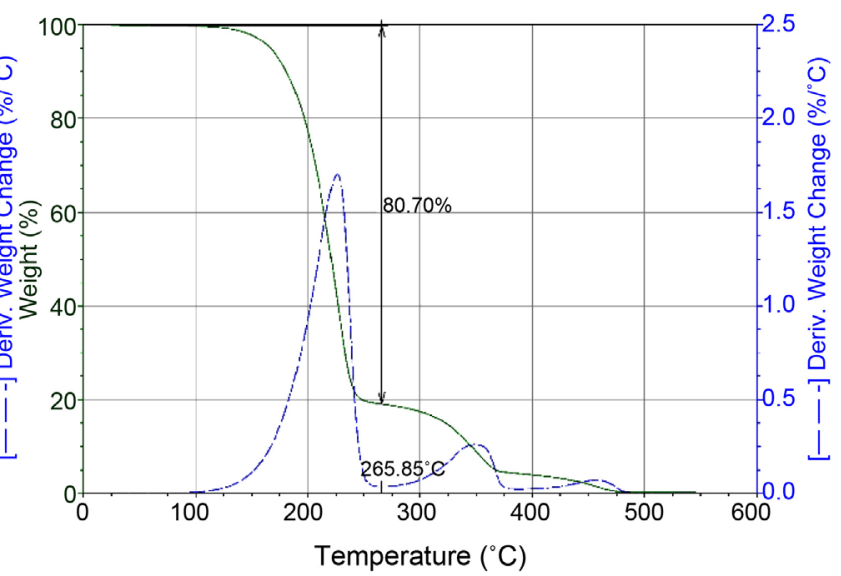

(d)

Figure 2. Typical TGA thermographs for biodiesel production over the mixing time: (a) $1 \mathrm{~min}$, (b) $5 \mathrm{~min}$, (c) $10 \mathrm{~min}$, (d) $20 \mathrm{~min}$. 


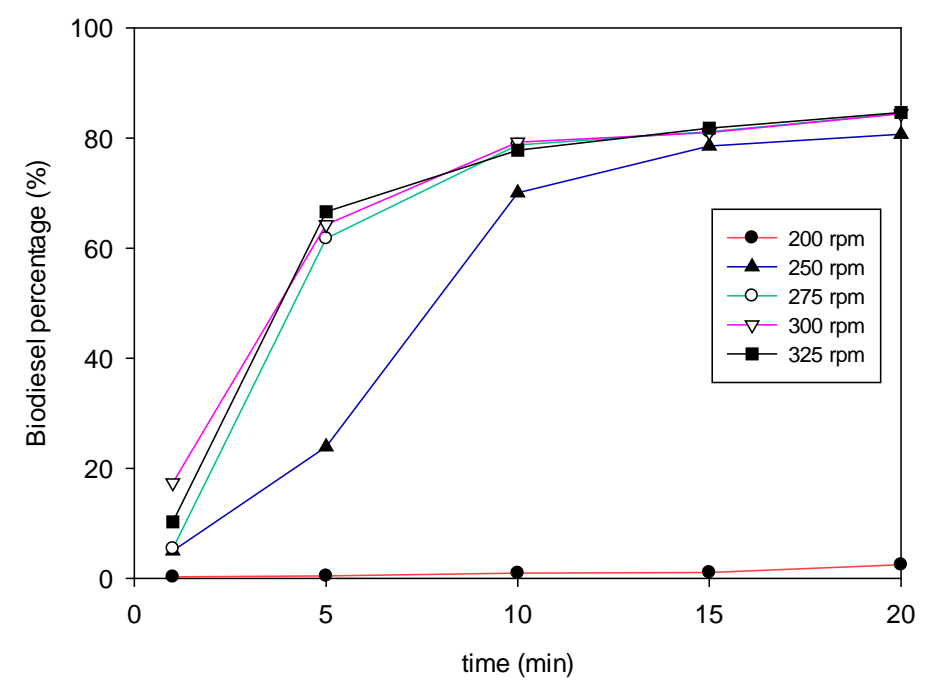

Figure 3. Biodiesel yields measured by TGA under different agitation intensities.

to the very low reaction rate at the start of the process due to the mass transfer limitations between methanol and oil phase [18]. As mixing continued the transesterification between the canola oil and methanol began and biodiesel yield increased. This was because the mixing process enabled the dissolution of alcohol and oil, thereby increasing reaction rates [19]. Lesser yield was observed at lower agitation intensity and shorter reaction time, which was supported by Hosseini, Nikbakht [20], who demonstrated that increasing agitation speed led to an increasing contact between oil and alcohol molecules and faster mass transfer, which is a key step in the transesterification process.

After 5 min's agitation, weight losses as indicated by TGA shows only $0.47 \%$ biodiesel was produced at $200 \mathrm{rpm}$, while up to $66.63 \%$ biodiesel was obtained when mixing intensity reached to $325 \mathrm{rpm}$ for the same time duration. Experimental evidence showed that with an increase of mixing intensity, biodiesel yield increased accordingly after 5 min's agitation. As mixing continued for $10 \mathrm{~min}$ marginal increase in biodiesel yield was observed for lower rpm. For instance, $0.98 \%$ yield was observed when agitation speed was at $200 \mathrm{rpm}$, but significantly higher yield of $70.06 \%$ and $78.75 \%$ were obtained at 250 and $275 \mathrm{rpm}$, respectively. A comparison of the mean biodiesel yield using Tukey-Kramer HSD shows that there is no significant difference $(\mathrm{p}>0.05)$ in yield beyond $275 \mathrm{rpm}$. This is evident in the less than $1.5 \%$ variation in the biodiesel yield at 300 and $325 \mathrm{rpm}$. Similar minimum variation was observed at higher mixing time.

\subsection{Analytical Evaluation Using Refractive Index}

\section{Calibration of Refractometer}

The refractometer was calibrated using the standard pure biodiesel (B100) and canola oil from 0 to $100 \%$ with an interval of $20 \%$. The linear relationship between the biodiesel conversion percentage and refractive index is shown in Figure 4. The linear regression equation for determining the biodiesel yield used in 


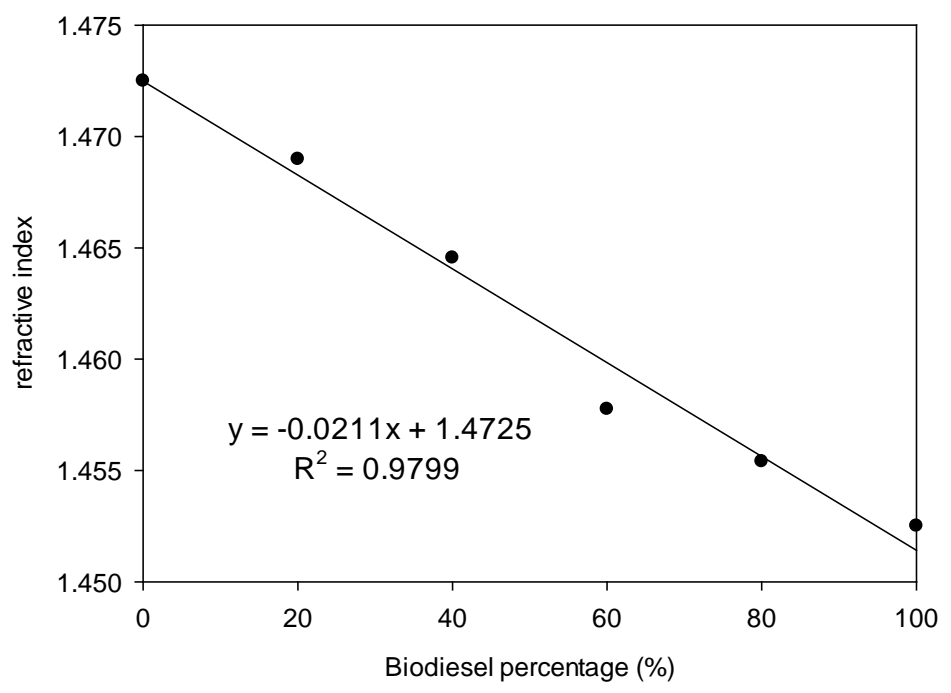

Figure 4. Refractive index calibration using standard biodiesel.

the experiment is shown in Equation (3). The estimated coefficient of determination shows that $97.99 \%$ of the variation in the refractive indexes could be explained by the variation in biodiesel yield thus indicating the statistical reliability of the linear model.

As illustrated in Figure 4, there was a linear correlation between the conversion of the oil and the hydroxyl content or the refractive index. Such a linear correlation verifies further the reliability of the method. Thus, the suggested correlation could allow for the determination of the conversion to methylesters in the transesterification process by measuring the hydroxyl content or the refractive index.

\subsection{Biodiesel Yield Estimation and Analysis}

The computed biodiesel yields from measured refractive indexes at five agitation intensities as a function of agitation time is shown in Figure 5. The result shows that both mixing time and mixer impeller speed increases biodiesel yield. Although, relatively low amount of biodiesel was observed at lower mixing speed, the recorded yield was up to 5 times higher than that value by the thermogravimetric approach. Up to $88 \%$ biodiesel yield could be achieved when the rpm higher than 250. Like the thermogravimetric analysis, a comparison of the mean biodiesel yield using Tukey-Kramer HSD shows that there is no significant difference $(\mathrm{p}>0.05)$ in yield beyond $275 \mathrm{rpm}$ with less than $5 \%$ variation at all mixing times.

\subsection{Comparative Evaluation of the Two Analytical Methods}

\subsubsection{Resources}

Thermogravimetric techniques for biodiesel yield assessment have been a validated method for assessment reported by several authors. It is comparatively simple, requiring no sample preparation compared to the mainstream analytical 


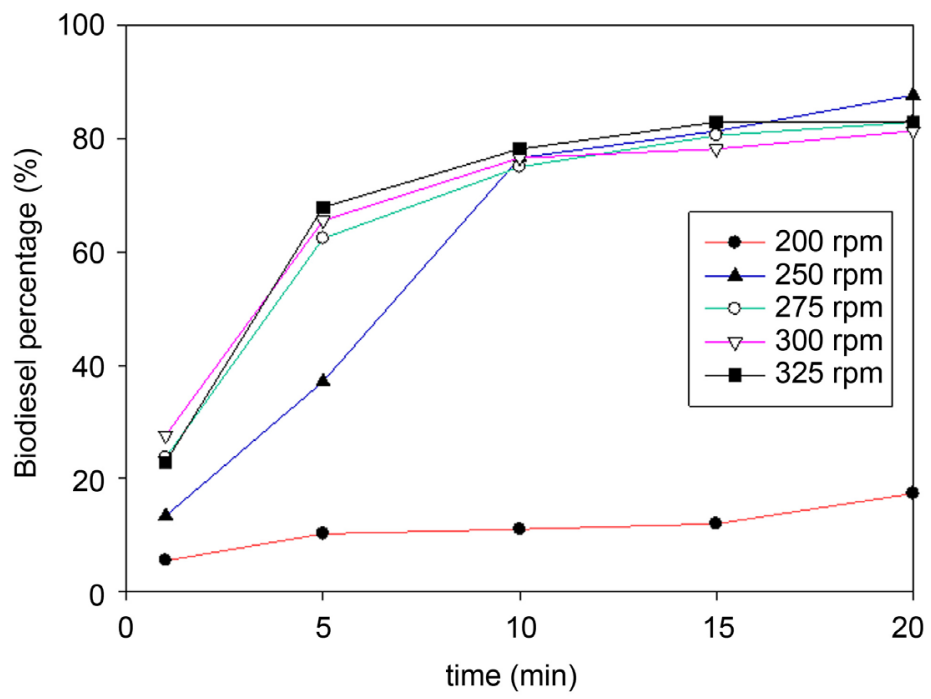

Figure 5. Biodiesel yields computed from measured refractive indexes under different agitation intensities and reaction times.

methods-Spectroscopy techniques. However, the cost of a thermal analyzer is more than $\$ 50,000$. In a well-established laboratory in developed countries, such equipment may be available but for laboratories and many developing countries thermal analyzer may not exist. On the other hand, a simple refractometer costs less than $\$ 100$ hence could be an alternative for the much complex and expensive analytical equipment.

Again, the average processing time for analysis using the TGA approach was $50 \pm 5$ min including prepping the equipment. The refractometer, in addition to requiring no sample preparation, less than a minute is required to determine the refractive index from which the yield is determined. Thus, the refractometer has the potential of providing a real time determination of the biodiesel yield.

\subsubsection{Biodiesel Yield}

Table 1 represents the statistical comparison between thermogravimetric analysis (TGA) and refractometer (RM) techniques. There was a generally good agreement between the yield determined by TGA and refractometer techniques. Overall, the variation in the mean yield for all agitation intensities and times were within $9 \%$. Meanwhile, the relationships between the conversions as determined TGA and refractive indexes of the products at each agitation speed were investigated. The biodiesel yields computed from measured refractive indexes were plotted as a function of the TGA yields as seen in Figure 6. The refractometer measured biodiesel yields were found to be very close to TGA measured values. The linear fit between the two data series results in an average $R^{2}$ value of 0.93 for all agitation intensities and reaction times, which support this finding.

Although both methods predicted lowest yields at an agitation intensity of 200 rpm, TGA measured yields were only $0.3 \%-2.5 \%$ ( $1.1 \%$ on average), while computed values from refractive indexes were $5.5 \%-17.3 \%$ ( $11.2 \%$ on average). 
Table 1. Statistical comparison of thermogravimetric analysis (TGA) and refractometer (RM) techniques.

\begin{tabular}{ccccc}
\hline \multirow{2}{*}{ RPM } & \multicolumn{2}{c}{ Mean \% biodiesel } & PBIAS & $\mathrm{R}^{2}$ \\
\cline { 2 - 3 } & TGA & RM & & \\
\hline 200 & 1.1 & 11.2 & $-918 \%$ & 0.85 \\
250 & 51.3 & 58.7 & $-14 \%$ & 0.95 \\
275 & 62.3 & 64.9 & $-4 \%$ & 0.92 \\
300 & 65.3 & 65.9 & $-1 \%$ & 0.96 \\
325 & 64.2 & 67.0 & $-4 \%$ & 0.96 \\
\hline
\end{tabular}
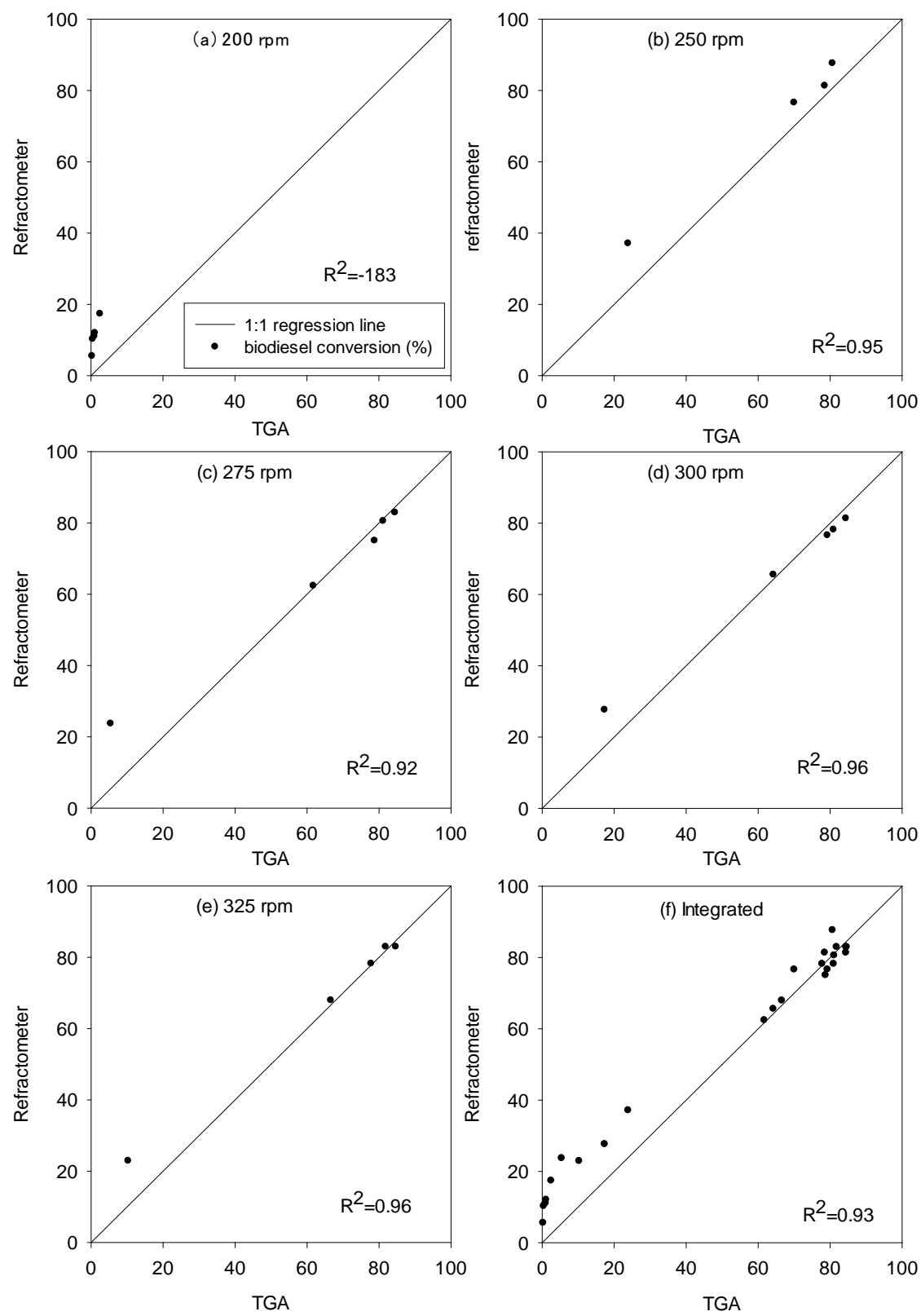

Figure 6. Comparison between TGA and refractometer measured biodiesel conversion (\%) from transesterification in canola oil and methanol under agitations of (a) $200 \mathrm{rpm}$, (b) $250 \mathrm{rpm}$, (c) $275 \mathrm{rpm}$, (d) $300 \mathrm{rpm}$, (e) $325 \mathrm{rpm}$ and (f) all treatments. 
It should be noted that the PBIAS of biodiesel yields between two methods were extremely high (-918\%) and $R^{2}$ was 0.85 (Table 1 ), indicating terrible match and significant difference of the two measurements at $200 \mathrm{rpm}$ when reaction time was within $20 \mathrm{~min}$.

When agitation intensity was increased to $250 \mathrm{rpm}$, average biodiesel yields measured by TGA and refractometer increased to $51.3 \%$ and $58.7 \%$, respectively. The difference between two measurements was within $15 \%$ and $R^{2}$ was 0.95 . Lower PBIAS were found when agitation speed continued to increase to 275 $325 \mathrm{rpm}$, with percent difference between $1 \%-4 \%$ and $R^{2}$ from $0.92-0.96$.

In general, the biodiesel yields computed from measured refractive indexes were comparable to TGA measure values, and both methods provided similar trend of increasing yields with elevating agitation intensities. As illustrated in Figure 6 and Table 1, there was a linear correlation between the biodiesel conversion measured from TGA and refractometer. Such linear correlation of the two methods demonstrated the reliability of refractometer compared to TGA. Nevertheless, each sample takes at least one hour to be analyzed from TGA, while the refractometer gives results within a few seconds. Therefore, despite the high sensitivity of TGA technique, it is hard to monitor the reactions in real time, while refractometer could provide reliable and comparable results with low cost and less time.

\subsection{Modeling the Biodiesel Yield}

The biodiesel yield data was fitted to an exponential rise model shown in Equation (3) to predict the biodiesel yield as a function of the mixing time.

$$
Y=a\left(1-e^{-b t}\right)
$$

where $Y$ represents the biodiesel yield and a represents a mixing constant reflecting agitator resistance and $\mathrm{b}$ represents the rate of biodiesel yield.

The result shows that the model was a good fit for predicting biodiesel yield using mixing time. The model parameters shown in Table 2 indicate a general rise in the rate of biodiesel production as the agitation speed increased in both evaluation methods. This increase in the rates may be attributed to the mass transfer limitations between methanol and oil phase. As expected, a general

Table 2. Biodiesel prediction rate constants.

\begin{tabular}{ccccccc}
\hline \multirow{2}{*}{ RPM } & \multicolumn{3}{c}{ TGA } & & \multicolumn{3}{c}{ RM } \\
\cline { 2 - 7 } & $a$ & $b$ & $R^{2}$ & $a$ & $b$ & $R^{2}$ \\
\hline 200 & 1539 & $6.82 \mathrm{E}-05$ & 0.85 & 14.23 & 0.0254 & 0.67 \\
250 & 107.10 & 0.0807 & 0.94 & 98.67 & 0.1194 & 0.97 \\
275 & 86.59 & 0.2152 & 0.96 & 81.24 & 0.3014 & 0.99 \\
300 & 84.17 & 0.2728 & 0.99 & 79.08 & 0.3850 & 0.99 \\
325 & 85.20 & 0.2528 & 0.97 & 82.79 & 0.3319 & 0.99 \\
\hline
\end{tabular}


decline in the agitation resistance " $b$ " was observed as speed increased. It is important to note that there was a wide variation in the two methods at lower speed, thus it supports the earlier assertion that the refractometer over predicts at lower speed. The changes in model parameter " $a$ " and " $b$ " were not significantly different $(\mathrm{p}<0.05)$ at higher speeds $(\mathrm{rpm}>275)$. Overall, the rate of biodiesel yield was relatively higher with the refractometer technique compared to the TGA. The rate of biodiesel yield ranged from $0.000068-0.2528$ and $0.0254-$ 0.3850 per minute for thermogravimetric and refractometer techniques, respectively. Some investigators had also observed the higher rates and decreased agitation resistance which have been described as shorter delay in FAME appearance with increasing agitation speed [20] [21] [22] [23].

\section{Conclusion}

This paper examined the potential of using a refractometer to measure the biodiesel yield in real time from the transesterification reaction in canola oil and methanol with the presence of $\mathrm{KOH}$ as the catalyst. The computed biodiesel yields under five different agitation intensities and five reaction times were compared with the measured values by TGA. Our results indicated that the values measured from the two methods were comparable within 9\% difference on average for all agitation intensities and reaction times. The linear fit between the two data series results in an average $R^{2}$ value of 0.93 . The linear regression between TGA biodiesel yields and refractometer measured yields suggests that the refractometer can accurately quantify the amount of biodiesel present. Finally, compared with TGA method, using the refractometer for monitoring the transesterification of vegetable oils with methanol has comparable accuracy and it is faster, more convenient and cheaper than TGA method with portable devices, which makes it a more appropriate method for real-time process monitor purposes.

\section{Conflicts of Interest}

The authors declare no conflicts of interest regarding the publication of this paper.

\section{References}

[1] Da Conceicao, L.R.V., et al. (2011) Obtaining and Characterization of Biodiesel from Jupati (Raphia taedigera Mart.) Oil. Fuel, 90, 2945-2949. https://doi.org/10.1016/j.fuel.2011.04.019

[2] Mittelbach, M. (1996) Diesel Fuel Derived from Vegetable Oils, VI: Specifications and Quality Control of Biodiesel. Bioresource Technology, 56, 7-11. https://doi.org/10.1016/0960-8524(95)00172-7

[3] Costa Neto, P.R., et al. (2004) Quantification of Soybean Oil Ethanolysis with $1 \mathrm{H}$ NMR. Journal of the American Oil Chemists' Society, 81, 1111-1114. https://doi.org/10.1007/s11746-004-1026-0

[4] Chand, P., et al. (2009) Thermogravimetric Quantification of Biodiesel Produced 
via Alkali Catalyzed Transesterification of Soybean Oil. Energy \& Fuels, 23, 989-992. https://doi.org/10.1021/ef800668u

[5] Shang, N.-C., et al. (2012) Characterization of Fatty Acid Methyl Esters in Biodiesel Using High-Performance Liquid Chromatography. Journal of the Taiwan Institute of Chemical Engineers, 43, 354-359. https://doi.org/10.1016/j.jtice.2011.11.005

[6] Farag, H., El-Maghraby, A. and Taha, N.A. (2012) Transesterification of Esterified Mixed Oil for Biodiesel Production. International Journal of Chemical and Biochemical Sciences, 2, 105-114.

[7] Venkat Reddy, C.R., Oshel, R. and Verkade, J.G. (2006) Room-Temperature Conversion of Soybean Oil and Poultry Fat to Biodiesel Catalyzed by Nanocrystalline Calcium Oxides. Energy \& Fuels, 20, 1310-1314. https://doi.org/10.1021/ef050435d

[8] Xie, W. and Li, H. (2006) Hydroxyl Content and Refractive Index Determinations on Transesterified Soybean Oil. Journal of the American Oil Chemists' Society, 83, 869-872. https://doi.org/10.1007/s11746-006-5039-5

[9] Andrade, R.D.A., et al. (2012) Thermal Behavior of Diesel/Biodiesel Blends of Biodiesel Obtained from Buriti Oil. Acta Scientiarum. Technology, 34, 243-248.

https://doi.org/10.4025/actascitechnol.v34i2.12797

[10] Furuta, S., Matsuhashi, H. and Arata, K. (2006) Biodiesel Fuel Production with Solid Amorphous-Zirconia Catalysis in Fixed Bed Reactor. Biomass and Bioenergy, 30, 870-873. https://doi.org/10.1016/j.biombioe.2005.10.010

[11] Dubé, M., Tremblay, A. and Liu, J. (2007) Biodiesel Production Using a Membrane Reactor. Bioresource Technology, 98, 639-647. https://doi.org/10.1016/j.biortech.2006.02.019

[12] Du, Z., et al. (2011) Microwave-Assisted Pyrolysis of Microalgae for Biofuel Production. Bioresource Technology, 102, 4890-4896. https://doi.org/10.1016/j.biortech.2011.01.055

[13] Ullah, F., Bano, A. and Ali, S. (2013) Optimization of Protocol for Biodiesel Production of Linseed (Linum usitatissimum L.) Oil. Polish Journal of Chemical Technology, 15, 74-77. https://doi.org/10.2478/pjct-2013-0013

[14] Meher, L., Dharmagadda, V.S. and Naik, S. (2006) Optimization of Alkali-Catalyzed Transesterification of Pongamia pinnata Oil for Production of Biodiesel. Bioresource Technology, 97, 1392-1397. https://doi.org/10.1016/j.biortech.2005.07.003

[15] Qiu, F., et al. (2011) Biodiesel Production from Mixed Soybean Oil and Rapeseed Oil. Applied Energy, 88, 2050-2055. https://doi.org/10.1016/j.apenergy.2010.12.070

[16] Frascari, D., et al. (2008) A Pilot-Scale Study of Alkali-Catalyzed Sunflower Oil Transesterification with Static Mixing and with Mechanical Agitation. Energy \& Fuels, 22, 1493-1501. https://doi.org/10.1021/ef700584h

[17] Moriasi, D.N., et al. (2007) Model Evaluation Guidelines for Systematic Quantification of Accuracy in Watershed Simulations. Transactions of the ASABE, 50, 885-900. https://doi.org/10.13031/2013.23153

[18] Hou, X., et al. (2007) Lewis Acid-Catalyzed Transesterification and Esterification of High Free Fatty Acid Oil in Subcritical Methanol. Korean Journal of Chemical Engineering, 24, 311-313. https://doi.org/10.1007/s11814-007-5052-x

[19] Hosseini, M., Nikbakht, A.M. and Tabatabaei, M. (2012) Biodiesel Production in Batch Tank Reactor Equipped to Helical Ribbon-Like Agitator. Modern Applied Science, 6, 40. https://doi.org/10.5539/mas.v6n3p40

[20] Noureddini, H. and Zhu, D. (1997) Kinetics of Transesterification of Soybean Oil. Journal of the American Oil Chemists' Society, 74, 1457-1463. 
https://doi.org/10.1007/s11746-997-0254-2

[21] Von Blottnitz, H., Sadat-Rezai, S. and Vardy, J. (2004) Conversion of Plant Oils to Methyl-Ester Fuels: Consideration for Reactor Design in Commercial and Small-Scale Production. 16th International Congress of Chemical and Process Engineering, 22-26 August 2004, Prague, Czech Republic.

[22] Vicente, G., et al. (2005) Kinetics of Sunflower Oil Methanolysis. Industrial \& Engineering Chemistry Research, 44, 5447-5454. https://doi.org/10.1021/ie040208j

[23] Stamenković, O.S., et al. (2007) The Effect of Agitation Intensity on Alkali-Catalyzed Methanolysis of Sunflower Oil. Bioresource Technology, 98, 2688-2699.

https://doi.org/10.1016/j.biortech.2006.09.024 